\title{
Relationships Among Pain Disability, Pain Intensity, Illness Intrusiveness, and Upper Extremity Disability in Patients With Traumatic Peripheral Nerve Injury
}

Christine B. Novak, PhD, Dimitri J. Anastakis, MD, Dorcas E. Beaton, PhD, Susan E. Mackinnon, MD, Joel Katz, PhD

Purpose In patients with a peripheral nerve injury, a simple conceptualization assumes that pain disability is determined by pain intensity. This study evaluated the relationships among pain intensity, illness intrusiveness, and pain disability.

Methods After we obtained ethics board approval, we enrolled English-speaking adult patients who had experienced an upper extremity peripheral nerve injury 0.5 to 15 years previously. Patients completed the Disabilities of the Arm, Shoulder, and Hand (DASH), Illness Intrusiveness Scale, Pain Disability Index, and McGill Pain questionnaires. We used multivariate linear regression to evaluate the variables that predicted pain disability.

Results There were 124 patients ( 41 women, 83 men; mean $\pm \mathrm{SD}, 41 \pm 16$ y of age). The median time since injury was 14 months (range, 6-145 months), and there were 43 brachial plexus nerve injuries. Mean \pm SD scores were: pain disability, $29 \pm 18$; illness intrusiveness, $40 \pm 18$; DASH, $45 \pm 22$; and pain intensity, $4.6 \pm 3.0$. The pain disability, DASH, and illness intrusiveness scores were significantly higher in patients with brachial plexus injuries than in those with distal nerve injuries $(\mathrm{p}<.05)$. There was strong correlation between pain disability and DASH $(r=0.764, p<.001)$ and illness intrusiveness $(r=0.738, p<.001)$ and a weaker correlation with pain intensity $(\mathrm{r}=0.549, \mathrm{p}<.001)$. The final regression model predicting pain disability scores explained $70 \%$ of the variance with these predictors: DASH $(\beta=0.452, \mathrm{p}<.001)$, illness intrusiveness $(\beta=0.372, \mathrm{p}<.001)$, and pain intensity $(\beta=$ $0.143, \mathrm{p}=.018)$.

Conclusions Pain disability was substantial after nerve injury, and pain intensity explained the least variance among the model variables. Pain intensity should be considered only one component of pain, and the impact of pain in the context of disability should be considered in patients with chronic nerve injury. ( $J$ Hand Surg 2010;35A:1633-1639. Copyright $\odot 2010$ by the American Society for Surgery of the Hand. All rights reserved.)

Type of study/level of evidence Prognostic IV.

Key words Peripheral nerve, injury, pain disability, upper extremity. 
$\mathrm{T}$ RAUMATIC PERIPHERAL NERVE injuries can result in motor dysfunction, sensory dysfunction, and pain with substantial impairment and upper extremity disability. ${ }^{1-6}$ Upper extremity disability is frequently assessed with the Disabilities of the Arm, Shoulder, and Hand (DASH) questionnaire; in patients with peripheral nerve injuries, high levels of disability have been reported. ${ }^{1,6}$ Pain has been strongly associated with upper extremity disability in patients after nerve, elbow, and wrist injury. ${ }^{6-8}$ Many of these studies reported substantial upper extremity disability as measured by the DASH, although the extent to which pain interferes with life domains and the extent to which the injury-related physical impairment interferes with life domains were not reported.

Pain disability relates to the negative impact of pain on life domains such as work, family and home responsibilities, recreation, social activity, and self-care. High levels of pain disability have been reported in patients with musculoskeletal disorders and facial pain. ${ }^{9-13} \mathrm{~A}$ simple conceptualization of the relationship between pain disability and pain intensity assumes that pain disability is primarily determined by pain intensity. However, the relationship between pain disability and pain intensity after traumatic upper extremity peripheral nerve injury has yet to be evaluated.

Life domains may be affected by pain after traumatic nerve injury, but these domains may also be affected by physical impairment or other injury-related factors. The concept of illness intrusiveness refers to the interference in life domains as a result of illness or treatment-related factors. ${ }^{14}$ Devins et al. reported evidence of illness intrusiveness in patients with various medical and surgical pathologies and reported the impact of these symptoms on specific life domains. ${ }^{15-19}$ Motor and sensory impairments that may occur with upper extremity nerve injury may interfere with life domains. Illness intrusiveness has not been previously evaluated in patients with peripheral nerve injury, nor have the relationships among illness intrusiveness, disability, and pain intensity.

The purpose of this study was to test the relationships among pain disability, pain intensity, illness intrusiveness, and upper extremity disability after a traumatic peripheral nerve injury in a multivariate model. Specifically, we were interested in evaluating subtle but important aspects of pain and disability. We hypothesized that pain disability, illness intrusiveness, and upper extremity disability would be substantial, and that illness intrusiveness would be a stronger predictor of pain disability than would pain intensity.

\section{MATERIALS AND METHODS}

After we obtained approval from our institutional research ethics boards, we invited adult patients who had experienced a traumatic upper extremity peripheral nerve injury between 6 months and 15 years previously to participate in this study. Exclusion criteria were amputation injury or an upper motor neuron lesion, and the lack of ability to understand the English-language questionnaires. A total of 128 consecutive patients were invited to participate in the study when the study coordinator was present at the clinic; 4 patients declined to participate.

After the patients signed informed consent forms, as part of a battery of tests they were asked to complete the DASH, the Illness Intrusiveness Rating Scale, the Pain Disability Index, and the Short-Form McGill Pain Questionnaire (SF-MPQ).

\section{Outcome measures}

The Pain Disability Index is a 7-item questionnaire designed to assess the extent to which pain interferes with daily life domains (family and home responsibilities, recreation, social activity, occupation, sexual behavior, self-care, and life-support activity). ${ }^{20-22}$ Each item is ranked on a scale of 0 (no disability) to 10 (total disability). The Pain Disability Index is calculated with summation of the scores from each item (score range from 0 to 70); a higher score indicates a higher level of pain disability. High internal consistency (0.86), modest test-retest reliability (0.44), and good concurrent validity have been reported with the Pain Disability In$\operatorname{dex}^{20-25}$

The Illness Intrusiveness Rating Scale is a 13-item questionnaire that evaluates the extent to which a disease (or treatment) interferes with various life domains (such as health, diet, work, recreation, financial situation, and relationships). ${ }^{14,16}$ The patient is asked to indicate the extent to which the illness or treatment interferes with each activity, on a scale of 1 (not very much) to 7 (very much). A total illness intrusiveness score (range, 13-91) may be calculated; a higher score indicates a greater impact of the illness on life domains. The validity and reliability of the Illness Intrusiveness Rating Scale have been established in patients with medical and surgical conditions. ${ }^{15,16,19,26,27}$

The DASH is a 30 -item questionnaire that assesses disability. Each item is ranked on a 5-point scale. A total score is calculated (range, $0-100$ ); higher DASH scores reflect higher levels of disability. Good reliability and validity have been reported with the DASH. ${ }^{28-32}$ 
We used the SF-MPQ to assess pain. ${ }^{33-35}$ Patients were asked to rank each adjective (11 sensory and 4 affective) on a scale from none (0) to severe (3), and a Pain Rating Index was calculated. Pain intensity was indicated on a $10-\mathrm{cm}$ visual analog scale (VAS) from 0 (no pain) to 10 (worst possible pain).

\section{Statistical analysis}

Descriptive data are presented as means and SDs for continuous variables and frequency counts for categorical variables. We used parametric (Pearson) or nonparametric (Spearman) correlations to evaluate associations among the DASH, Pain Disability Index, Illness Intrusiveness Rating Scale, VAS pain intensity, age, and time since injury. We used $t$-tests to compare outcome scores (pain disability, pain intensity, illness intrusiveness, and DASH) among the independent variables of workers' compensation or litigation involvement (yes vs no) and dominant hand affected (yes vs no). We used a one-way analysis of variance to compare the outcome scores of patients with brachial plexus injuries, single shoulder nerve injuries, and distal nerve injuries (median, ulnar, and radial). A significant $(\mathrm{p}<.05) \mathrm{F}$ test (main effect) was followed up with Tukey's post hoc $t$-tests to determine the pattern of significance among the 3 means.

We employed multivariate linear regression using manual backward elimination to evaluate the variables that predicted pain disability as measured by the Pain Disability Index. The initial model included the following independent variables: illness intrusiveness, DASH, VAS pain intensity, workers' compensation or litigation involvement, dominant hand affected, time since injury, gender, age, work status, and nerve injured. We assumed collinearity between variables when they correlated greater than 0.8 . We performed manual backward elimination using the beta coefficient $\mathrm{p}$ value (.1 or greater to remove a variable); the final model included only the variables with a $p$ value of .1 or less. We used forward entry multiple regression to investigate the unique variance accounted for by each significant variable included in the final model.

We performed statistical analyses with SPSS (version 15.0 for Windows; SPSS, Inc., Chicago, IL).

\section{RESULTS}

Table 1 presents the demographic data. There were 124 patients ( 83 men and 41 women) with an age of $41 \pm$ 16 years (range, $18-80 y$ ). Time since injury was $24 \pm$ 27 months (median, $14 \mathrm{mo}$; range, 6-145 mo). The brachial plexus was injured in 43 cases, and the dominant arm was involved in 66 patients. Table 2 presents

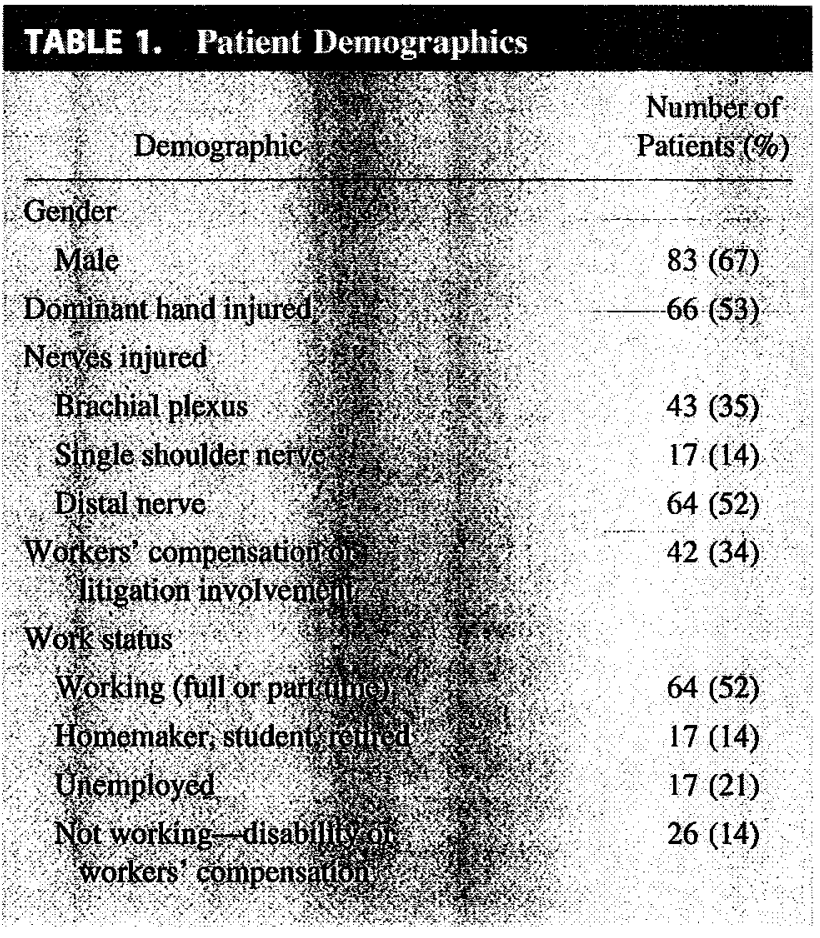

the scores for each outcome measure (Pain Disability Index, Illness Intrusiveness Rating Scale, DASH, and VAS pain intensity). The mean Pain Rating Index from the SF-MPQ was $13.9 \pm 10.8$ (sensory, $11.1 \pm 8.1$; affective, $2.8 \pm 3.2$ ). High levels of pain disability, illness intrusiveness, and the DASH were reported, and we found high internal consistency in these measures: Pain Disability Index $(\alpha=.91)$, Illness Intrusiveness Rating Scale $(\alpha=.92)$, and DASH $(\alpha=.96)$.

\section{Relationships among pain disability, pain intensity, illness intrusiveness, and DASH}

There was a strong correlation between pain disability and illness intrusiveness $(r=0.738, p<.001)$ and DASH ( $\mathrm{r}=0.764, \mathrm{p}<.001$ ) (Table 3 ). We found a weaker correlation between pain disability and pain intensity $(\mathrm{r}=0.549, \mathrm{p}<.001)$.

Relationships among patient factors and pain intensity, illness intrusiveness, and disability

The ANOVA results showed a significant main effect of injury (brachial plexus, single shoulder, and distal nerve injuries) for DASH ( $\mathrm{F}=9.2$, degrees of freedom $[\mathrm{df}]=2, \mathrm{df}=123, \mathrm{p}<.001)$ and the illness intrusiveness score $(\mathrm{F}=4.3, \mathrm{df}=2, \mathrm{df}=123, \mathrm{p}=.015)$ and the pain disability score $(\mathrm{F}=2.9, \mathrm{df}=2, \mathrm{df}=123, \mathrm{p}=$ .059) approaching the conventional level of significance. Post hoc analyses revealed that the DASH $(\mathrm{p}<.001)$, illness intrusiveness score $(\mathrm{p}=.01)$, and pain 


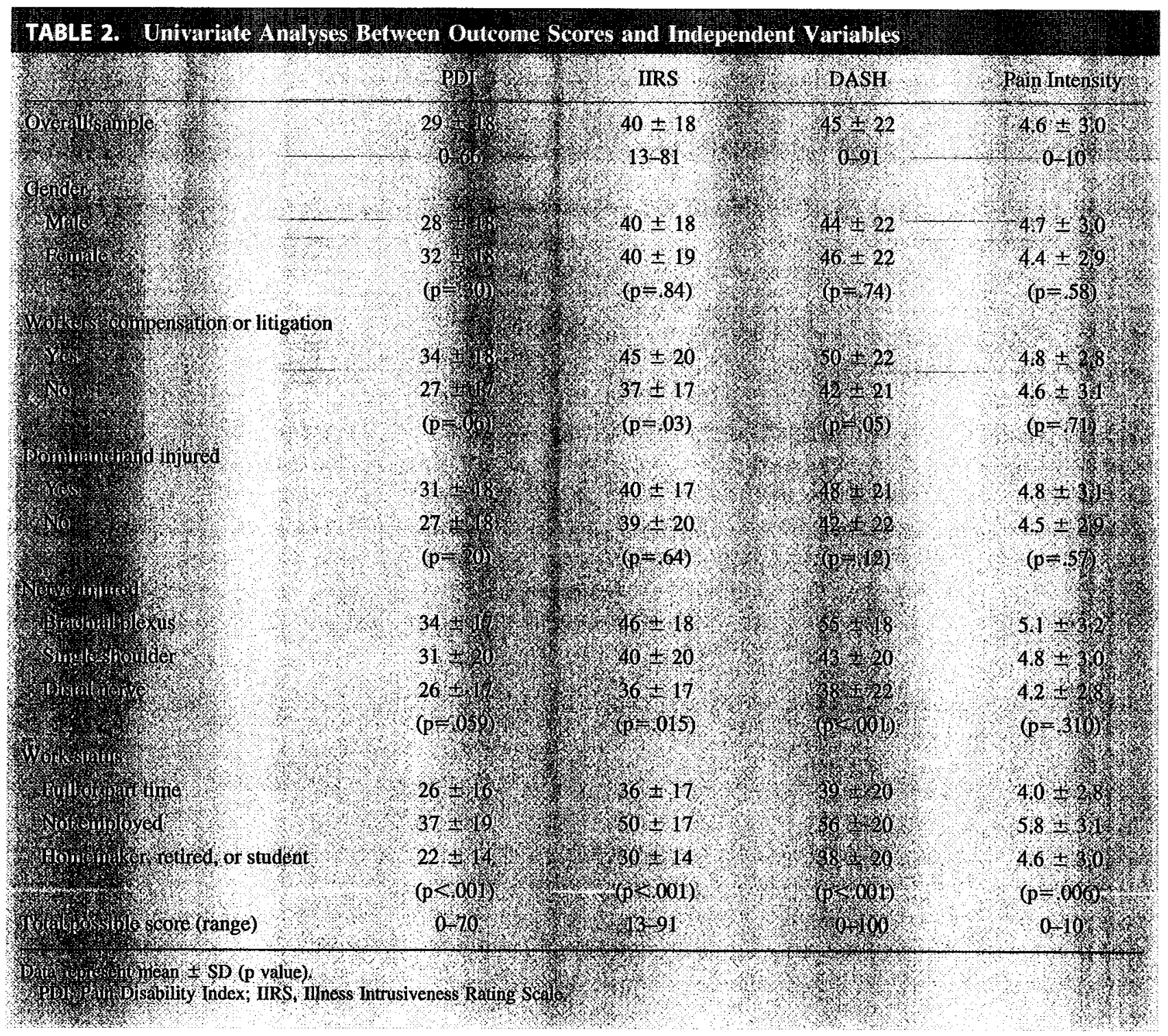

disability scores $(p=.05)$ were significantly higher in patients with brachial plexus injuries compared with distal nerve injuries.

The illness intrusiveness $(\mathrm{p}=.03)$ and DASH scores $(\mathrm{p}=.05)$ were significantly higher in patients with workers' compensation or litigation involvement compared with patients without workers' compensation or with no litigation (Table 2). Comparisons of the outcome scores between patients with the dominant versus nondominant hand affected revealed no significant differences (Table 2). We found a weak correlation between time since injury and VAS pain intensity $(\mathrm{r}=$ $0.20, p=.02$ ) and no significant correlation between time since injury and DASH, pain disability, or illness intrusiveness (Table 3). There were no significant correlational relationships between age and DASH, pain disability, illness intrusiveness, or VAS pain intensity.

\section{Multivariate regression}

We used multivariate linear regression to evaluate factors associated with pain disability as measured by the Pain Disability Index. None of the correlation coefficients between independent variables (gender, workers' compensation or litigation involvement, dominant hand injured, time since injury, age, nerve(s) injured, illness intrusiveness, DASH, and VAS pain intensity) was greater than 0.8 , and therefore multicollinearity was not evident. We performed tests for normality on the continuous variables. Time since injury (skewness of 2.75) was positively skewed, with a mean of 24 months and median of 14 months. A log 10 tranformation corrected the nonnormality, and we used these data in the regression analyses. We used manual backward elimination to eliminate variables until the final regression model had been reached. The preliminary regression model in- 


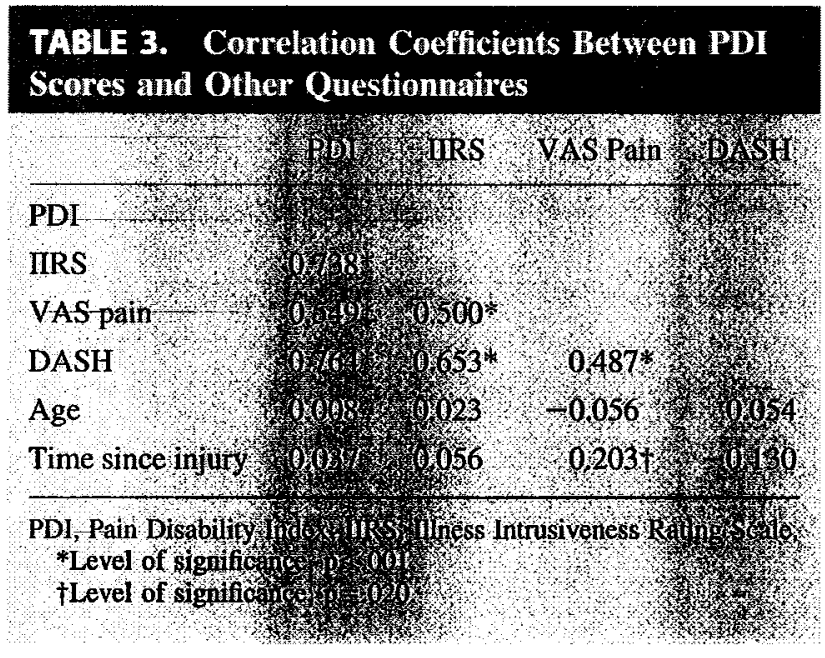

cluded the following independent variables: gender, workers' compensation or litigation involvement, work status, dominant hand injured, time since injury, age, nerve(s) injured, Illness Intrusiveness Rating Scale, DASH, and VAS pain intensity. With manual backward elimination and .1 level of significance for removal, the final regression model predicting pain disability scores explained $69.9 \%$ of the variance (Table 4 ) and included the following predictor variables: DASH $(\beta=.452, \mathrm{p}<.001)$, Illness Intrusiveness Rating Scale $(\beta=.372, \mathrm{p}<.001)$, and VAS pain intensity $(\beta=.143$, $\mathrm{p}=.018)$. As single predictors, the explained variance was higher with the DASH $\left(r^{2}=0.57\right)$ and illness intrusiveness $\left(\mathrm{r}^{2}=0.55\right)$ and less with pain intensity $\left(r^{2}=0.30\right)$. To assess the influence of each of these predictors, we used a forward entry regression model: VAS pain intensity (step 1), Illness Intrusiveness Rating Scale (step 2), and DASH (step 3). The change in variance with the addition of each variable was VAS pain intensity $\left(r^{2}\right.$ change $=0.30$ ), illness intrusiveness $\left(r^{2}\right.$ change $\left.=0.287\right)$, and DASH $\left(r^{2}\right.$ change $\left.=0.11\right)$. After controlling for pain intensity and illness intrusiveness, the DASH still explained a large proportion of the variance in the Pain Disability Index. To assess for possible content overlap in the pain questions between the Pain Disability Index and DASH, we also performed the final regression analysis using the DASH scores with 4 pain-related questions removed. The explained variance was $68.6 \%$, and the change in variance with the addition of the variable with the DASH score (pain-related questions removed) was $9.8 \%\left(\mathrm{r}^{2}\right.$ change $=$ 0.098), indicating that the variance was not due to item overlap between these questionnaires.

\section{DISCUSSION}

In this group of patients with chronic nerve injury who had experienced trauma at least 6 months previously, there was substantial pain disability, illness intrusiveness, and upper extremity disability. In the final regression model, illness intrusiveness, upper extremity disability, and pain intensity were predictors of pain disability. After controlling for the influences of pain intensity and illness intrusiveness, upper extremity disability as measured by the DASH still accounted for a substantial amount of pain disability (11\% of the variance). Therefore, disability associated with pain comprises more than pain intensity and also includes the impact of the injury on life domains.

Many patients with traumatic nerve injury continue to have long-term morbidity related to muscle weakness, sensory dysfunction, and pain. ${ }^{1,4-6,36-40}$ Depending on the nature and severity of the residual impairments, specific life domains and health-related quality of life may be affected. ${ }^{41}$ Illness intrusiveness arises as a result of the interfering effects of illness or treatmentrelated factors on multiple life domains. ${ }^{14,15} \mathrm{We}$ found high levels of illness intrusiveness in patients after traumatic upper extremity nerve injuries. Irish et al. reported a mean illness intrusiveness score of 21 in patients who used obturator prostheses after primary palatal defect reconstructions. ${ }^{17}$ Fong et al. evaluated illness intrusiveness and quality of life in patients with chronic renal disease. The mean illness intrusiveness score was 17 in patients treated with home hemodialysis, compared with 15 in patients receiving peritoneal dialysis. $^{42}$ In our study, the mean Illness Intrusiveness Rating Scale score was 40 , which suggests a high level of illness intrusiveness in patients with upper extremity nerve injury, compared with previous reports involving patients with palatal defects and chronic renal disease. Therefore, in patients with chronic nerve injury, morbidity associated with the injury affects life domains.

Pain is a subjective symptom that is assessed by patient report. There are various pain measurement tools, including verbal rating scales (VRS), numeric rating scales (NRS), VAS, and multidimensional questionnaires such as the MPQ. These scales provide an indication of pain intensity and pain quality (such as burning and aching) but do not assess the impact of pain on life domains or the psychosocial factors that may be associated with pain. The Pain Disability Index provides a patient-reported measure to assess the impact of pain on life domains; it has not been previously reported in patients with peripheral nerve injury. ${ }^{20,21}$ We found high Cronbach's alpha $(\alpha=0.91)$ with the Pain Disability Index, which supports the use of this questionnaire in patients with nerve injury. The present sample of patients with chronic nerve injury reported a mean Pain Disability Index score of 29 and mean VAS pain 
TABLE 4. Final Multivariable Regression Model Using Manual Backward Elimination

(Dependent Variable: Pain Disability Index)

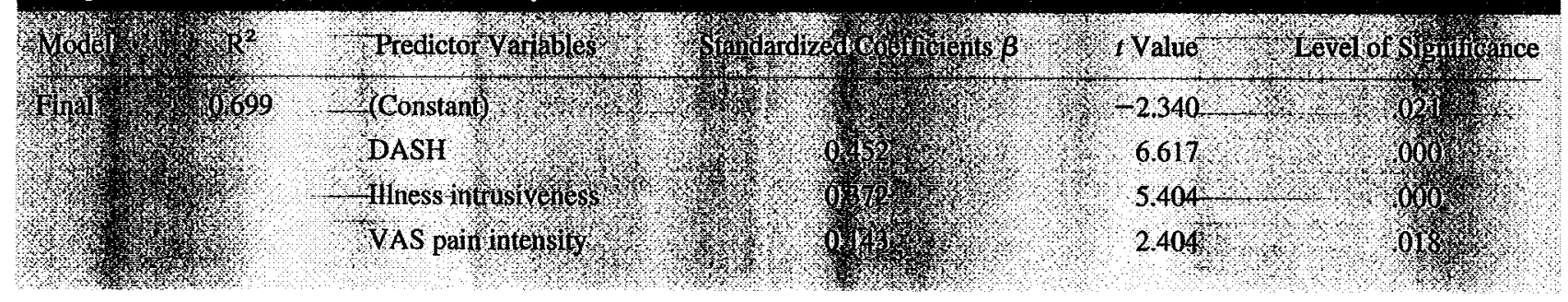

intensity of $4.6 \mathrm{~cm}$. Similar values of pain disability and pain intensity were reported in patients with low back pain. ${ }^{10}$ Gronblad et al. evaluated pain disability and work-related factors in 107 patients with low back pain; the mean Pain Disability Index was 28 and the mean VAS pain intensity in the back was $47 \mathrm{~mm} .{ }^{10}$ Another study from the same institution reported a strong correlation between pain disability and pain intensity $(\mathrm{r}=$ 0.69). ${ }^{9}$ Turp et al. evaluated patients with facial pain, with an overall mean pain disability score of 22 (range, $0-70$ ) and higher pain disability scores in patients with more widespread pain. ${ }^{12}$ In that study, the significant predictors of the pain disability were pain distribution, pain intensity, and depression symptoms, with pain distribution having the most influence on pain disability. In the present study, we found a moderate correlation between the Pain Disability Index and VAS pain intensity ( $\mathrm{r}=0.55, \mathrm{p}<.001$ ), and pain intensity was a significant predictor of pain disability scores. Nevertheless, based on the standardized beta coefficients, illness intrusiveness and upper extremity disability were stronger predictors of pain disability. As a single predictor of Pain Disability Index scores, pain intensity accounted for only $30 \%$ of the variance, compared with illness intrusiveness, which explained $55 \%$ of the variance.

Limitations of this study include a cross-sectional design and inclusion of a select group of patients. The cross-sectional data present a single point of assessment; therefore, we cannot make conclusions regarding causality. The patients included in this study had experienced trauma at least 6 months previously, which represented a limited sample of patients who sought a medical opinion for assessment or treatment. There are patients who sustain a peripheral nerve injury and have complete recovery with no pain; these patients likely do not return for medical examination. However, there is wide variability in the clinical presentation of patients who do not have complete recovery, and it is our clinical impression that these patients are most challenging to manage.
In this study, patients with traumatic upper extremity nerve injuries had substantial pain disability, upper extremity disability, and illness intrusiveness. Pain disability was associated with pain intensity, illness intrusiveness, and upper extremity disability. We recommend that pain intensity be considered as only one component of pain, and in the context of disability, the impact of this pain should be included in the assessment of patients with chronic nerve injury.

\section{REFERENCES}

1. Ahmed-Labib M, Golan JD, Jacques L. Functional outcome of brachial plexus reconstruction after trauma. Neurosurgery 2007:61: 1016-1023.

2. Berman JS, Birch R, Anand P. Pain following human brachial plexus injury with spinal cord root avulsion and the effect of surgery. Pain 1998;75:199-207.

3. Cocito D, Paolasso I, Tavella A, Poglio F, Ciaramitaro P, Scarmozzino A, et al. Pain affects the quality of life of neuropathic patients. Neurol Sci 2006;27:155-160.

4. Htut M, Misra P, Anand P, Birch R, Carlstedt T. Pain phenomena and sensory recovery following brachial plexus injury and surgical repairs. J Hand Surg 2006;31B:596-605.

5. Kitajima I, Doi K, Hattori Y, Takka S, Estrella E. Evaluation of quality of life in brachial plexus injury patients after reconstructive surgery. Hand Surg 2006;11:103-107.

6. Novak CB, Anastakis DJ, Beaton DE, Katz J. Patient reported outcome following peripheral nerve injury. J Hand Surg 2009;34A: 281-287.

7. Doornberg JN, Ring D, Fabian LM, Malhotra L, Zurakowski D, Jupiter JB. Pain dominates measurements of elbow function and health status. J Bone Joint Surg 2005;87A:1725-1731.

8. Souer JS, Lozano Calderon SA, Ring D. Predictors of wrist function and health status after operative treatment of fractures of the distal radius. J Hand Surg 2008;33A:157-163.

9. Gronblad M, Hupli M, Wennerstrand P, Jarvinen E, Lukinmaa A, Kouri J-P, et al. Intercorrelation and test-retest reliability of the Pain Disability Index (PDI) and the Oswestry Disability Questionnaire (ODQ) and their correlation with pain intensity in low back pain patients. Clin J Pain 1993;9:189-195.

10. Gronblad M, Jarvinen E, Hurri H, Hupli M, Karaharju EO. Relationship of the Pain Disability Index (PDI) and the Oswestry Disability Questionnaire (ODQ) with three dynamic physical tests in a group of patients with chronic low-back and leg pain. Clin J Pain 1994;10:197-203.

11. Gronblad M, Jarvinen E, Airaksinen O, Ruuskanen M, Hamalainen $H$, Kouri J-P. Relationship between subjective disability with pain intensity, pain duration, pain location, and work-related factors in nonoperated patients with chronic low back pain. Clin J Pain 1996; 12:194-200. 
12. Turp JC, Kowalski CJ, Stohler CS. Greater disability with increased pain involvement, pain intensity and depressive preoccupation. Eur $\mathrm{J}$ Pain 1997:1:271-277.

13. Anagnostis C, Gatchel RJ, Mayer TG. The Pain Disability Questionnaire. A new psychometrically sound measure for chronic musculoskeletal disorders. Spine 2004;29:2290-2302.

14. Devins GM. Illness intrusiveness and the psychosocial impact of lifestyle disruptions in chronic life-threatening disease. Adv Ren Repl Ther 1994;1:251-263.

15. Devins GM, Bezjak A, Mah K, Loblaw DA, Gotowiec AP. Context moderates illness-induced lifestyle disruptions across life domains: a test of illness intrusiveness theoretical framework in six common cancers. Psycho Oncol 2006;15:221-233.

16. Devins GM, Dion R, Pelletier LG, Shapiro CM, Abbey S, Raiz LR, et al. Structure of lifestyle disruptions in chronic disease. A confirmatory factor analysis of the Illness Intrusiveness Ratings Scale. Med Care 2001;39:1097-1104.

17. Irish JC, Sandhu N, Simpson C, Wood R, Gilbert R, Gullane PJ, et al. Quality of life in patients with maxillectomy prostheses. Head Neck 2009;31:813-821.

18. Katz MR, Irish JC, Devins GM, Rodin GM, Gullane PJ. Psychosocial adjustment in head and neck cancer: the impact of disfigurement, gender and social support. Head Neck 2002;25:103-112.

19. Poochikian-Sarkissian S, Sidani S, Wennberg R, Devins GM. Seizure freedom reduces illness intrusiveness and improves quality of life in epilepsy. Can J Neurol Sci 2008;35:280-286.

20. Tait RC, Pollard CA, Margolis RB, Duckro PN, Krause SJ. The Pain Disability Index: psychometric and validity data. Arch Phys Med Rehabil 1987;68:438-441.

21. Tait RC, Chibnall JT, Krause SJ. The Pain Disability Index: psychometric properties. Pain 1990;40:171-182.

22. Pollard CA. Preliminary validity study of the Pain Disability Index. Percept Mot Skills 1984;59:974.

23. Chibnall JT, Tait RC. The Pain Disability Index: factor structure and normative data. Arch Phys Med Rehabil 1994;75:1082-1086.

24. Chibnall JT, Tait RC. Confirmatory factor analysis of the Pain Catastrophizing Scale in African American and Caucasian workers' compensation claimants with low back injuries. Pain 2005;113:369 375.

25. Tait RC, Chibnall JT. Factor structure of the Pain Disability Index in Workers' Compensation claimants with low back injuries. Arch Phys Med Rehabil 2005;86:1141-1146.

26. Klimidis S, Minas IH, Yamamoto K. Impact of Illness Scale: reliability, validity, and cross-cultural utility. Comp Psychiatr 2001:42: $416-423$.

27. Novak M, Mah K, Molnar MZ, Ambrus C, Csepanyi G, Kovacs A et al. Factor structure and reliability of the Hungarian version of the llness Intrusiveness Rating Scale invariance across North American and Hungarian dialysis patients. J Psychosom Res 2005;58:103-110.
28. Beaton DE, Katz JN, Fossel AH, Wright JG, Tarasuk V, Bombardier C. Measuring the whole or the parts? Validity, reliability and responsiveness of the Disabilities of the Arm, Shoulder and Hand outcome measure in different regions of the upper extremity. J Hand Ther 2001;14:128-146.

29. Dias JJ, Rajan RA, Thompson JR. Which questionnaire is best: the reliability, validity and ease of use of the patient evaluation measure, the Disabilities of the Arm, Shoulder and Hand and the Michigan hand outcome measure. J Hand Surg 2008:33B:9-17.

30. Hudak PL, Amadio PC, Bombardier C. Development of an upper extremity outcome measure: the DASH (Disabilitics of the Arm. Shoulder and Hand). Am J Ind Med 1996:29:602-608.

31. SooHoo NF, McDonald AP, Seiler JG, McGillivary GR. Evaluation of construct validity of the DASH questionnaire by correlation to the SF-36. J Hand Surg 2008;27A:537-541.

32. Gummesson C, Atroshi I, Ekdahl C. The Disabilities of the Arm, Shoulder and Hand (DASH) outcome questionnaire: Iongitudinal construct validity and measuring self-rated health change after surgery. BMC Musculoskel Disord 2003:4:11-16.

33. Melzack R. The McGill Pain Questionnaire: major properties and scoring methods. Pain 1975;1:277-299.

34. Melzack R. The short-form McGill Pain Questionnaire. Pain 1987; 30:191-197.

35. Grafton KV, Foster NE, Wright CC. Test-retest reliability of the short-form McGill Pain Questionnaire. Clin J Pain 2005;21:73-82.

36. Kato N, Htut M, Taggart M, Carlstedt T, Birch R. The effects of operative delay on the relief of neuropathic pain after injury to the brachial plexus. J Bone Joint Surg 2006;88B:756-759.

37. Leechavengvongs $S$, Witoonchart $K$, Uerpairojkit $C$, Thuvasethakul $P$, Ketmalasiri W. Nerve transfer to biceps muscle using a part of the ulnar nerve in brachial plexus injury (upper arm type): a report of 32 cases. J Hand Surg 1998;23A:711-716.

38. Mackinnon SE, Novak CB, Myckatyn TM, Tung TH. Results of reinnervation of the biceps and brachialis muscles with a double fascicular transfer for elbow flexion. J Hand Surg 2005;30A:978985.

39. Novak CB, Mackinnon SE, Tung TH. Patient outcome following a thoracodorsal to musculocutaneous nerve transfer for reconstruction of elbow flexion. Br J Plast Surg 2003;55:416-419.

40. Tung TH, Novak CB, Mackinnon SE. Nerve transfers to the biceps and brachialis branches to improve elbow flexion strength after brachial plexus injuries. J Neurosurg 2003;98:313-318

41. Bailey R, Vaskutas V, Fox I, Baum CM, Mackinnon SE. Effect of upper extremity nerve damage on activity participation, pain, depression and quality of life. J Hand Surg 2009;34A:1682-1688.

42. Fong E, Bargman JM, Chan CT. Cross-sectional comparison of quality of life and illness intrusiveness in patients who are treated with home hemodialysis versus peritoneal dialysis. Clin J Am Soc Nephrol 2007;2:1195-1200. 